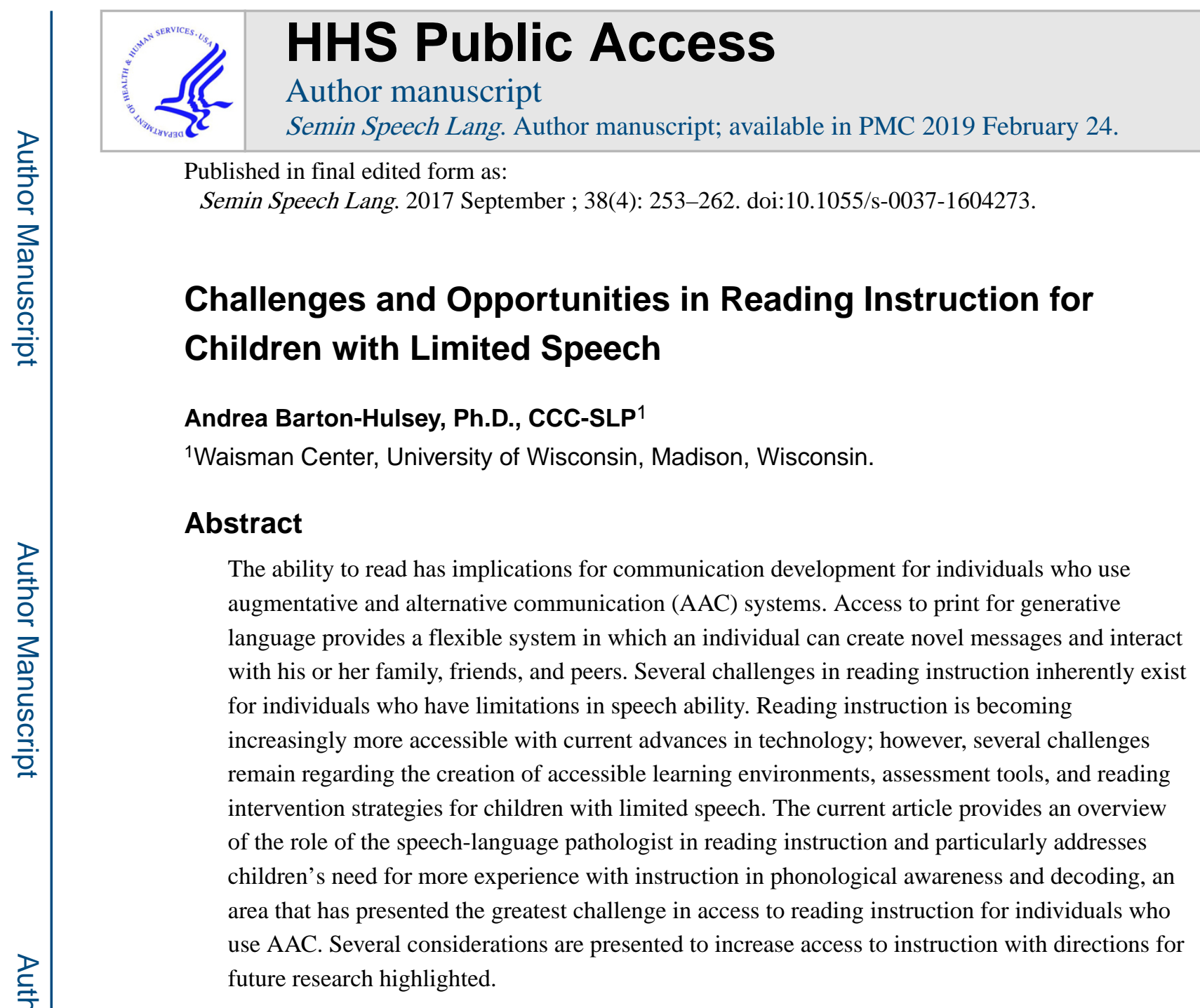

\title{
Keywords
}

Augmentative and alternative communication; intellectual and developmental disability; phonological awareness; reading; decoding

\begin{abstract}
Reading skills are fundamental to a child's access to print for academic growth, interaction with society and to provide an alternate mode of communication for each of us in today's ever advancing world of technology. From preschool through third grade, children are typically taught fundamental skills to learn to read. By third grade and beyond, children use reading skills to acquire new academic knowledge. According to the National Assessment of Adult Literacy, ${ }^{1} 55 \%$ of adults with below basic literacy skills did not graduate from high school. Twenty-one percent of adults with below basic literacy skills had multiple disabilities. It is estimated that more than $15 \%$ of children in the United States have one or more developmental disabilities that impacts their reading development, ${ }^{2}$ and $1.3 \%$ of the population have a disability that impacts their ability to use speech as a primary means of
\end{abstract}

Address for correspondence: Andrea Barton-Hulsey, Ph.D., 1500 Highland Ave., Room 531, Madison, WI 53717 (andreabarton@waisman.wisc.edu).

Augmentative and Alternative Communication: From Research to Practice; Guest Editor, Kathryn D.R. Drager, Ph.D., CCC-SLP. 
communication, ${ }^{3}$ making augmentative and alternative communication (AAC) systems an important component of their daily lives.

The ability to read has implications for communication development for individuals who use AAC systems. Access to print for generative language provides a flexible system in which to create novel messages and interact with families, friends, and peers. The National Reading Panel provides guidance on best practices for teaching reading to typically developing children via the "what works clearinghouse"; ${ }^{4}$ however, little research has been done to determine how children with limited speech ability develop reading skills, how they can participate in traditional reading instruction, and the most effective ways to teach reading to individuals with limited speech ability.

Important work to date regarding reading intervention for children who use AAC systems has focused on language instruction to build comprehension of vocabulary, grammar, and story structure. ${ }^{5}$ Several studies to date demonstrate engaging approaches with books to encourage language learning in combination with children's AAC systems, ${ }^{6-8}$ although limited work to date has evaluated approaches in teaching skills of phonological awareness and word decoding. ${ }^{9,10}$ Research examining language learning within book-reading contexts has created a foundation in which to explore the additive effect of instruction in phonological awareness and decoding to build word-reading skills in children with limited speech.

The simple view of reading characterizes reading ability as the product of language comprehension and word decoding. ${ }^{11}$ Very few studies to date have examined the impact of teaching both comprehension and decoding skills within an intervention to children with limited speech. Machalicek and colleagues identified 18 studies with children who use AAC aimed at targeting overall literacy skills. ${ }^{5}$ A range of study targets and outcomes were reported, with half of the studies aimed at increasing the frequency or complexity of AAC symbols used for communication during book reading. The remaining nine studies reported a range of intervention focus from learning letter-sound correspondence to reading single words in print. A 2012 review of the literature regarding the use of phonological awareness strategies for individual word-reading instruction for children who use AAC yielded eight articles with 26 total children with limited speech. ${ }^{12}$ Using the same search criteria as Barker and colleagues, ${ }^{12}$ five additional studies with 34 additional children have since been published that systematically taught phonological awareness or decoding skills to children who have limited speech and use AAC. ${ }^{13-17}$ This article provides an overview of the role of phonological awareness and decoding instruction within reading intervention and the role of the speech-language pathologist in instruction. This article particularly addresses children's experience with instruction in phonological awareness and decoding, an area that has presented the greatest challenge in access to reading instruction for individuals who use AAC. Reading instruction is becoming increasingly more accessible due to current advances in technology; however, several challenges remain regarding the creation of accessible learning environments, assessment tools, and reading intervention strategies for children with limited speech. Finally, several directions for future research are highlighted. 


\section{PHONOLOGICAL AWARENESS}

Phonological awareness is the explicit knowledge of the sound structure of a language and the ability to manipulate those sounds. ${ }^{18}$ Stages of phonological awareness are suggested to initially consist of a child's identification of words that rhyme, then knowing that words are comprised of component sounds (e.g., cat begins with $/ \mathrm{k} /$ ), and then the understanding that words are comprised of specific sound segments, that when blended together make a whole word $($ e.g., $/ \mathrm{k} / / \mathfrak{/} / \mathrm{t} / \mathrm{c}$ cat $) .{ }^{19}$ Children need foundational skills of phonological awareness such as rhyme and segmenting to build reading skills. ${ }^{18}$ Children bring this knowledge to activities involving printed letters and words. As children gain experience with print, they are provided a visual system to map their phonological knowledge onto and gain lettersound awareness. Children not only learn specific one-to-one letter sound correspondence but begin to learn that specific letter combinations represent different sounds than they may have originally learned in isolation (e.g.,sh $=/ \int /$ and not $/ \mathrm{s} / / \mathrm{h} /$ ). Additionally, morphological components of words are learned as having both specific sound and meaning properties (e.g., -ed,-ing). Context is important in learning to read, such that the vocabulary used for word decoding provides further support in deciphering written language. The interrelatedness between phonological awareness, vocabulary knowledge, and reading is depicted in Fig. 1 and is required for children to develop fluent reading. ${ }^{18}$ In reading development, semantic analysis occurs at all levels beginning with the phonology of a word, making reading an inherently linguistic task.

\section{CHILDREN WITH INTELLECTUAL AND DEVELOPMENTAL DISABILITY}

The systematic study of reading in individuals with intellectual and developmental disabilities (IDD) is a relatively recent area of research. Even more recent is the study of individuals with IDD who use AAC systems. Conners detailed the history of reading research for individuals with IDD. Prior to the 1990s a large focus of reading intervention involved whole-word approaches to reading instruction, with little success. ${ }^{20}$ These approaches did not take into consideration a child's ability to learn using phonological strategies. In the National Reading Panel's review of the effectiveness of reading approaches for typically developing children, approaches that consisted of a phonological core component in addition to instruction in language comprehension (i.e., the simple view of reading) yielded the most successful reading outcomes. ${ }^{4}$ In a recent review of evidence to date, the Institute for Education Sciences National Center for Special Education Research found that phonological skills support reading success for children with IDD in the same way as they do for children who are typically developing. ${ }^{21}$ Continued research with children with IDD who have limitations in speech is needed to determine the contributions of experience with print, phonological awareness, and language comprehension to reading success or failure.

\section{CHILDREN WITH LIMITED SPEECH ABILITY}

Limited speech ability occurs in children with and children without intellectual disability. They have a range of etiological diagnoses that impact the speech they are able to produce. They may have a range of motor abilities; some children are able to use an index finger to 
directly select a symbol on an AAC system, and others may require the use of eye gaze technology. All children with significant limitations in speech, however, are unable to functionally communicate with their peers, family members, and community using oral language. AAC systems have been successfully introduced to children with delays in speech and language development during early intervention to support both language comprehension and production. ${ }^{22}$ Additionally, these systems have been critical tools for language intervention during preschool to encourage continued language development, classroom participation, and social engagement with peers. ${ }^{23-25} \mathrm{AAC}$ systems are an intervention approach. ${ }^{26} \mathrm{AAC}$ systems not only provide an output mode for communication from the child, but can dually act as an input mode for language learning and comprehension when also used by the communication partner.

Recent updates to the National Joint Committee for the Communication Needs of People with Severe Disabilities (NJC) Communication Bill of Rights identify literacy instruction as an important intervention target to support learning, health, well-being, employment, and functioning in society. ${ }^{27}$ The authors call upon practitioners, educators, and researchers to integrate inclusive practices, increase aware ness, conduct research, and inform clinical practice in literacy as 1 of 12 critical areas of focus for individuals with severe disabilities. The Communication Bill of Rights emphasizes that all children have the right to access reading instruction. ${ }^{28}$

Children who have limited speech present unique challenges to reading instruction that speech-language pathologists and teachers must work together to navigate. Instruction in reading, writing, and literacy is within the scope of practice of speech-language pathologists.

${ }^{29}$ The American Speech-Language Hearing Association provides guidance to speechlanguage pathologists on their role in reading instruction for children, stating that "speechlanguage pathologists play a critical and direct role in the development of literacy for children and adolescents with communication disorders, including those with severe or multiple disabilities." ${ }^{29}$ Ensuring access to instruction, adequate assessment of reading ability, and progress monitoring are critical opportunities for speech-language pathologists to support children's right to reading intervention so they may develop to their fullest potential.

\section{ACCESS TO INSTRUCTION}

Children who use AAC systems have been found to have 2 out of every 10 experiences with books and instruction in basic literacy skills when compared with their siblings without limitations in speech. ${ }^{30}$ Special education teachers have been found to have a range of perspectives on literacy instruction for students with disabilities and significant speech impairment. ${ }^{31}$ In a survey conducted to evaluate teachers' perspectives on literacy instruction with children with limited speech ability who used AAC, teachers who taught kindergarten to twelfth-grade students rated literacy instruction that occurred during lifeskills-linked lessons more favorably than lessons that taught foundational skills for reading that included phonological awareness and decoding skills. Teachers were more likely to engage in activities that involved matching whole words to common objects and to teach text commonly found in community settings and on signs rather than engaging in activities of 
phonological awareness and print decoding. ${ }^{31}$ In a study that looked specifically at the quality of early literacy instruction in preschool classrooms serving students at risk for later learning or reading disabilities, teachers were found to have low quality of implementation of the reading curriculum materials they were using and failed to systematically and explicitly deliver reading instruction, including phonological awareness activities. ${ }^{32}$

In a typical classroom, teachers may use a range of strategies to engage students during reading activities. A typical preschool classroom may use group-based teaching sessions where students are asked to repeat after the teacher, identify a rhyming word in a song, or take turns identifying words that begin with the same sound. During elementary school, students may be called upon to sound out a word aloud or identify a sound that a group of letters make (e.g., ee =/i/). In third grade and beyond, children may be asked to read orally to the class. Each of these activities requires spoken language to participate. Technology provides us with several tools that can increase access to reading instruction for children who cannot participate in these traditional classroom activities via speech. In turn, teachers can create opportunities for participation using technology to provide input from the teacher or speech-language pathologist. Kent-Walsh and colleagues provide guidance for speechlanguage pathologists in adapting instructional activities to provide access and meaningful participation for students with limited speech ability while monitoring student progress. ${ }^{33}$ Adaptation begins by choosing a targeted skill and activity for teaching that skill. Next, assistive technologies that can be used in teaching are identified. Then, target vocabulary is selected along with an intervention technique such as aided input. Finally, tools for tracking student progress are identified. Several adaptations can be made to the mode of instruction to assist teachers and speech-language pathologists in providing access to reading activities, either with or without the support of electronic technology. Table 1 provides a range of tools that can be adapted to provide increased access to instruction for children with limited speech, specifically during activities of phonological awareness, letter and letter-sound naming, and word reading. Additionally, the Wisconsin Assistive Technology Initiative provides a list of commercially available tools that may be helpful in promoting access to reading instruction. ${ }^{34}$ Systematic evaluation and further research is needed to determine the effectiveness of these tools on reading outcomes. We know that a successful component of AAC intervention is the use of speech-generating devices (SGDs) to provide both an input and an output mode of communication for the child. ${ }^{35}$ Further research is warranted to determine if, like in AAC intervention, the use of SGDs or mobile apps that provide the child both an input and a productive output mode to express letter names and letter-sound relationships will provide increased learning during reading activities.

\section{CHALLENGES IN ASSESSMENT}

Currently, there are limited tools available for the assessment of phonological awareness and reading skills for individuals who cannot speak. To monitor progress in intervention, we must have methods of assessment that evaluate fundamental reading skills of phonological awareness and word reading. Several experimental tasks of phonological awareness have been developed and are presented in detail by Barker and colleagues. ${ }^{12}$ More recently, Barker et al have developed an experimental dynamic assessment tool of phonemic awareness via the alphabetic principle. ${ }^{36}$ Recently, Williams' Phonological and Print 
Awareness Scale has been published as the first standardized tool of its kind to measure rhyming, print knowledge, initial sound matching, final sound matching, and sound-symbol knowledge, all without the requirement of a spoken response, making it an appropriate tool for use with individuals with limited speech ability. ${ }^{37}$ Careful attention, however, should be given to the sensitivity and specificity in which standardized tools measure the skills of individuals with IDD given the language comprehension demands that are often inherent within these tools to complete assessment tasks. Guidance in assessment for individuals with severe disabilities provided by the NJC suggests that the use of informal instruments and procedures are often valuable in addition to standardized measures. ${ }^{27}$ Particularly, the use of dynamic assessment tools to evaluate progress in reading instruction may be more useful than standardized measures. For example, Allor and colleagues,${ }^{38}$ in a study with individuals with IDD, found that gains made in reading skill and phonological skill were not sensitive to the measures used on the Comprehensive Test of Phonological Awareness, ${ }^{39}$ but were measurable on the Dynamic Indicators of Basic Early Literacy Skills. ${ }^{40}$ Dynamic assessment tools allow the child experience with a particular concept, then evaluate the child's application of that knowledge via specific tasks. Dynamic assessment can inform instructional support needs and create optimal contexts for a child to learn new skills. ${ }^{27}$

Reading assessments are often a key component of literacy curriculum materials so that teachers can monitor progress and customize time spent on specific components of instruction. There are at least two reading curricula commercially available that are designed for teaching students with limited speech ability basic phonological awareness skills and decoding and that incorporate assessment within instructional modules. The Accessible Literacy Learning and Reading Program is available in both nonelectronic and electronic formats via the Accessible Literacy Learning and Reading Program app and consists of six basic components. ${ }^{41}$ Children are taught via visual supports blending and segmenting of sounds, letter-sound correspondence, single-word decoding, and sight word recognition. Words are then used in simple stories to provide further context for language learning. The Early Literacy Skills Builder and Early Reading Skills Builder curricula, both developed by Browder and colleagues, ${ }^{42,43}$ provide instruction in letter-sound identification, blending, segmenting and decoding words, and identifying sight words. The Early Reading Skills Builder Curriculum additionally provides assessment of reading comprehension within the curriculum. Further research is needed to determine the generalization of reading skills using these focused curricula and the utility of assessments provided within.

\section{CHALLENGES IN INSTRUCTION}

As in reading assessment, much of the research to date regarding reading intervention for children with limited speech ability has been done in focused contexts with limited numbers of students, using strategies that warrant further study. It is important to keep in mind that just as in any intervention approach with children who have severe disabilities and limited speech ability, several blended strategies may be warranted. There is no one-size-fits-all approach to instruction for children with limited speech. More longitudinal research is needed to expand our knowledge of instructional strategies that are effective in teaching phonological awareness and decoding skills that generalize to meaningful reading outcomes for children. Much of the work to date is focused on immediate results of single-word 
reading, with limited understanding of the impact of reading intervention on sentence comprehension. Furthermore, more research is warranted to determine effective methods that integrate a child's current AAC system within reading instruction. Foley and Pollatsek found that individuals who had access to speech-generating AAC systems performed better than individuals who were not speaking and not using speech generating AAC systems during reading instruction. ${ }^{44}$ Perhaps there is a reciprocal relationship involved in the production of speech using an SGD, and learning of its phonological components that these individuals benefitted from, similar to the relationship described by Romski and Sevcik, ${ }^{35}$ as a necessary component of language learning. SGDs provide access to language for communication resulting in the ability to have a turn in conversations with others. This experience with communication inevitably affects learning. If we view reading as a language task, children need experience using all parts of language, including the ability to break language into its phonetic parts, just as speaking children are afforded this practice to learn meaningful relationships between print and sounds. SGDs can be a tool for reading instruction. More research is needed to determine effective ways to integrate a child's current AAC system into reading instruction so that children have a consistent output mode to participate.

Currently, AAC systems provide little access to practice phonological skills. Keyboards that speak the sounds of letters could be made available as standard page sets to support access to the phonetic content of language. Currently, Word Wizard, an app by L'Escapadou, provides an example of a phonetic keyboard that allows a child to combine letters and simultaneously hear the resulting phonetic output, including changes in phonetic sounds when two letters are blended. For example, when the letters $c$ and $h$ are selected, their respective sounds are made independently. When the child presses the letter combination $c h$, the sound /t $\int /$ is produced. Fluent reading skills are developed when children have practice reading aloud. Students who use AAC are not able to learn to read in this way, but if they were provided access to language at the level of phonetic units, perhaps they could utilize this experience to develop greater reading skills.

Efficient readers have countless useful patterns in memory and translate these visual patterns to linguistic symbols. ${ }^{45}$ For children who use AAC, their knowledge of graphic symbol use may play a role in reading development. A child who uses an AAC system has had experience to understand that a symbol on the AAC system is a meaningful referent to a concept, object, or action in the environment. ${ }^{46,47}$ Children who use AAC may be advantaged in the ability to parse components of language (morphemes) that are required for reading comprehension. This understanding of the mappings between printed symbols and language components may play a role in children's transition to orthography when paired with instruction in phonological awareness and word decoding. An extensive look at how children use symbols to parse out the phonemic components of a word was done by Bishop and colleagues. ${ }^{46}$ The use of AAC symbols did not provide an advantage in learning phonological components of words, however, suggesting that this important skill of decoding must still be taught. Van Balkom and Verhoeven suggest that a single neural network is responsible for interpreting and storing meaning to visual, gesture, or speech information. ${ }^{48}$ If children learn to use AAC systems, perhaps this initial linguistic understanding in mapping meaning to print and beginning to organize the world into its 
component referential parts, regardless of a child's cognitive skill, could prepare the individual using AAC for learning phoneme-grapheme correspondences.

\title{
CONCLUSIONS AND FUTURE RESEARCH
}

Learning to read is a complex language task that is further complicated by the inability to produce speech. Children with limited speech do not have the same opportunities to participate in reading assessment and instruction as their same-age peers. Advances in technology have created opportunities for children who use AAC to participate using electronic keyboards that speak not only the names of letters but letter sounds. More research is needed to determine the benefit these tools may have during reading instruction. Children who use AAC may benefit from the simultaneous introduction of letters and sounds when learning to read, giving phonetic units of speech a tangible referent. The use of an AAC system may provide the child with initial understanding of the component parts of language and vocabulary involved in reading comprehension. The assessment of phonological awareness skills for children with limited speech, and the impact that experience with letters and letter sounds via an AAC system may have on reading development, is an area of critical need for future research.

\section{Acknowledgments}

\author{
DISCLOSURES
}

This publication was written with support from the Eunice Kennedy Shriver National Institute of Child Health and Human Development of the National Institutes of Health under Award Number T32HD007489 and P30HD03352 at the Waisman Center, University of Wisconsin-Madison. The content is solely the responsibility of the author and does not necessarily represent the official views of the National Institutes of Health.

\section{REFERENCES}

1. Kutner M, Greenberg E, Jin Y, Paulsen C. The health literacy of America's adults: results from the 2003 National Assessment of Adult Literacy. NCES 2006;6:1-59

2. Boyle CA, Boulet S, Schieve LA, et al. Trends in the prevalence of developmental disabilities in US children, 1997-2008. Pediatrics 2011;127(06): 1034-1042 [PubMed: 21606152]

3. Beukelman DR, Mirenda P. Principles of decision making, intervention and evaluation In: Augmentative and Alternative Communication: Supporting Children and Adults with Complex Communication Needs. Baltimore, MD: Brookes Publishing 2005:187-200

4. U.S. Department of Health and Human Services, National Institute on Child Health and Human Development. Report of the National Reading Panel (NIH Publication No. 004769). Available at: http://www.nichd.nih.gov/publications/pubs/nrp/documents/report.pdf. Accessed July 31, 2017

5. Machalicek W, Sanford A, Lang R, Rispoli M, Molfenter N, Mbeseha MK. Literacy interventions for students with physical and developmental disabilities who use aided AAC devices: a systematic review. J Dev Phys Disabil 2009;22(03):219-240

6. Binger C, Kent-Walsh J, Berens J, Del Campo S, Rivera D. Teaching Latino parents to support the multi-symbol message productions of their children who require AAC. Augment Altern Commun 2008;24(04):323-338 [PubMed: 18608143]

7. Browder DM, Ahlgrim-Delzell L, Courtade G, Gibbs SL, Flowers C. Evaluation of the Effectiveness of an early literacy program for students with significant developmental disabilities. Except Child 2008;75(01):33-52

8. Koppenhaver DA, Erickson KA, Skotko BG. Supporting communication of girls with Rett syndrome and their mothers in storybook reading. Int J Disabil Dev Educ 2001;48(04):395-410 
9. Coleman-Martin MB, Heller KW, Cihak DF, Irvine KL. Using computer-assisted instruction and the nonverbal reading approach to teach word identification. Focus Autism Other Dev Disabl 2005;20(02):80-90

10. Erickson K, Hanser G, Hatch P, Sanders E. Research-based practices for creating access to the general curriculum in reading and literacy for students with significant intellectual disabilities. Chapel Hill 2009;175

11. Hoover WA, Gough PB. The simple view of reading. Read Writ An Interdiscip J. 1990; 2:127-160

12. Michael Barker R, Saunders KJ, Brady NC. Reading instruction for children who use AAC: considerations in the pursuit of generalizable results. Augment Altern Commun 2012;28(03):160 170 [PubMed: 22946991]

13. Ahlgrim-Delzell L, Browder D, Wood L. Effects of systematic instruction and an augmentative communication device on phonics skills acquisition for students who are nonverbal. Educ Train Autism Dev Disabil 2014;49(04):517-532

14. Ahlgrim-Delzell L, Browder DM, Wood L, Stan-ger C, Preston AI, Kemp-Inman A. Systematic instruction of phonics skills using an iPad for students with developmental disabilities who are AAC users. J Spec Educ 2016;50(02):86-970

15. Bailey RL, Angell ME, Stoner JB. Improving literacy skills in students with complex communication needs who use augmentative / alternative communication systems. Educ Train Dev Disabil 2011;46(03):352-368

16. Benedek-Wood E, McNaughton D, Light J. Instruction in letter-sound correspondences for children with autism and limited speech. Top Early Child Spec Educ 2016;36(01):43-54

17. McCarthy JH, Hogan TP, Beukelman DR, Schwarz IE. Influence of computerized sounding out on spelling performance for children who do and do not rely on AAC. Disabil Rehabil Assist Technol 2015;10(03):221-230 [PubMed: 24512195]

18. Perfetti C. The universal grammar of reading. Sci Stud Read 2009;7(01):3-24

19. Ehri LC. Teaching phonemic awareness and phonics: an explanation of the national reading panel meta-analyses In: McCardle PE, Chhabra V, eds. The Voice of Evidence in Reading Research. Baltimore, MD: Paul H. Brookes; 2004:153-186

20. Conners FA. Reading instruction for students with moderate mental retardation: review and analysis of research. Am J Ment Retard 1992;96(06):577-597 [PubMed: 1344936]

21. Connor CM, Alberto PA, Compton DL, O'Connor RE. Improving reading outcomes for students with or at risk for reading disabilities: a synthesis of the contributions from the Institute of Education Sciences Research Centers. NCSER 2014-3000. Natl Cent Spec Educ Res 2014:108

22. Romski M, Sevcik RA, Adamson LB, et al. Randomized comparison of augmented and nonaugmented language interventions for toddlers with developmental delays and their parents. J Speech Lang Hear Res 2010;53(02):350-364 [PubMed: 20360461]

23. Binger C, Maguire-Marshall M, Kent-Walsh J. Using aided AAC models, recasts, and contrastive targets to teach grammatical morphemes to children who use AAC. J Speech Lang Hear Res 2011; 54(01):160-176 [PubMed: 20719874]

24. Kent-Walsh J, Binger C, Hasham Z. Effects of parent instruction on the symbolic communication of children using augmentative and alternative communication during storybook reading. Am J Speech Lang Pathol 2010;19(02):97-107 [PubMed: 20181850]

25. Hunt P, Soto G, Maier J, Müller E, Goetz L. Collaborative teaming to support students with augmentative and alternative communication needs in general education classrooms. AAC Augment Altern Commun 2002;18(01):20-35

26. Romski M, Sevcik RA. Augmentative communication and early intervention: Myths and realities. Infants Young Child 2005;18(03):174-185

27. Brady NC, Bruce S, Goldman A, et al. Communication services and supports for individuals with severe disabilities: guidance for assessment and intervention. Am J Intellect Dev Disabil 2016; 121(02):121-138 [PubMed: 26914467]

28. National Joint Committee for the Communication Needs of People with Severe Disabilities (NJC). Communication Bill of Right. Available at: http://www.asha.org/uploadedFiles/NJCCommunication-Bill-Rights.pdf. Accessed June 24, 2017 
29. American Speech-Language-Hearing Association. Roles and responsibilities of speech-language pathologists with respect to reading and writing in children and adolescents [Position Statement]. Available at: www.asha.org/policy. Accessed July 18, 2017

30. Koppenhaver DA, Pierce PL, Steelman JD, Yoder DE. Contexts of early literacy intervention for children with developmental disabilities. Language Intervention. 1995;5:241-274

31. Ruppar AL, Dymond SK, Gaffney JS. Teachers' perspectives on literacy instruction for students with severe disabilities who use augmentative and alternative communication. Res Pract Pers with Sev Disabil 2011;36(03):100-111

32. Justice LM, Mashburn A, Hamre B, Pianta R. Quality of language and literacy instruction in preschool classrooms serving at-risk pupils. Early Child Res Q 2008;23(01):51-68 [PubMed: 22773887]

33. Kent-Walsh J, Binger C, Soto G, Zangari C. Addressing the communication demands of the classroom for beginning communicators and early language users In: Practically Speaking: Language, Literacy and Academic Development for Students with AAC Needs; 2009:143-172

34. Wisconsin Assistive Technology Initiative. Chapter 7-Assistive Technology for Reading. Available at: http://www.wati.org/content/supports/free/pdf/Ch7-Reading.pdf. Accessed June 24, 2017

35. Romski M, Sevcik R. Breaking the Speech Barrier: Language Development through Augmented Means. Paul H. Brookes; 1996

36. Barker RM, Bridges MS, Saunders KJ. Validity of a non-speech dynamic assessment of phonemic awareness via the alphabetic principle. Augment Altern Commun 2014;30(01):71-82

37. Williams K. Phonological and Print Awareness Scale. Torrence, CA: Western Psychological Services; 2014

38. Allor JH, Mathes PG, Roberts JK, Cheatham JP, Champlin TM. Comprehensive reading instruction for students with intellectual disabilities: findings from the first three years. Psychol Sch 2010;47(05):445-466

39. Rashotte C, Torgesen JK, Wagner RK. Comprehensive Test of Phonological Processing. San Antonio, TX: Pearson; 1999

40. Good RH, Kaminski RA. Dynamic Indicators of Basic Early Literacy Skills, 6th ed. Eugene, OR 2002

41. Light JC, McNaughton D. ALL (Accessible Literacy Learning): Evidence-based Reading Instruction for Learners with Autism, Cerebral Palsy, Down Syndrome and Other Disabilities. Pittsburgh, PA: Mayer-Johnson; 2009

42. Browder DM, Gibbs SL, Ahlgrim-Delzell L, Courtade G, Lee A. Early literacy skills builder. Verona, WI: Attainment Company; 2007

43. Browder DM, Ahlgrim-Delzell L, Wood L. Early reading skills builder. 2015

44. Foley BE, Pollatsek A. Phonological processing and reading abilities in adolescents and adults with severe congenital speech impairments. Augment Altern Commun 1999;15:156-173

45. Perfetti C. Reading Ability. Oxford, UK: Oxford University Press; 1985

46. Bishop K, Rankin J, Mirenda P. Impact of graphic symbol use on reading acquisition. Augment Altern Commun 1994;10(02):113-125

47. Rankin J, Harwood K, Mirenda P. Influence of graphic symbol use on reading comprehension. Augment Altern Commun 1994;10(04):269-281

48. Van Balkom H, Verhoeven L. Literacy learning in users of AAC: a neurocognitive perspective. Augment Altern Commun 2010;26(03):149-157 [PubMed: 20874078] 


\section{Learning Outcomes:}

As a result of this activity, the reader will be able to (1) describe some of the challenges associated with reading instruction for individuals with limited speech ability; (2) discuss the importance of phonological awareness instruction for children with limited speech ability; and (3) explain the speech-language pathologist's role in supporting reading instruction for children who use augmentative and alternative communication systems. 


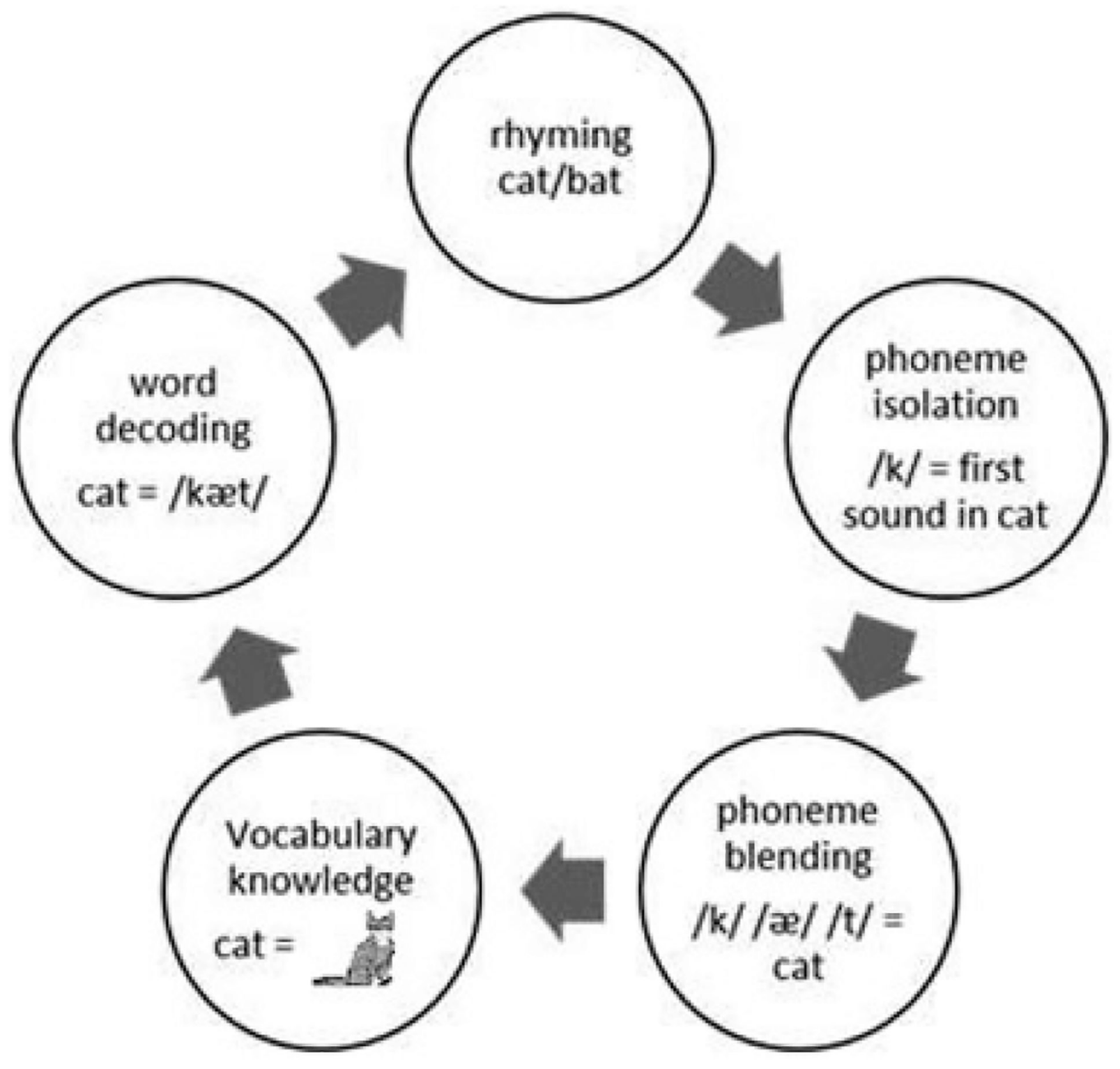

Figure 1.

Relationship between phonological awareness, vocabulary knowledge, and word reading. 


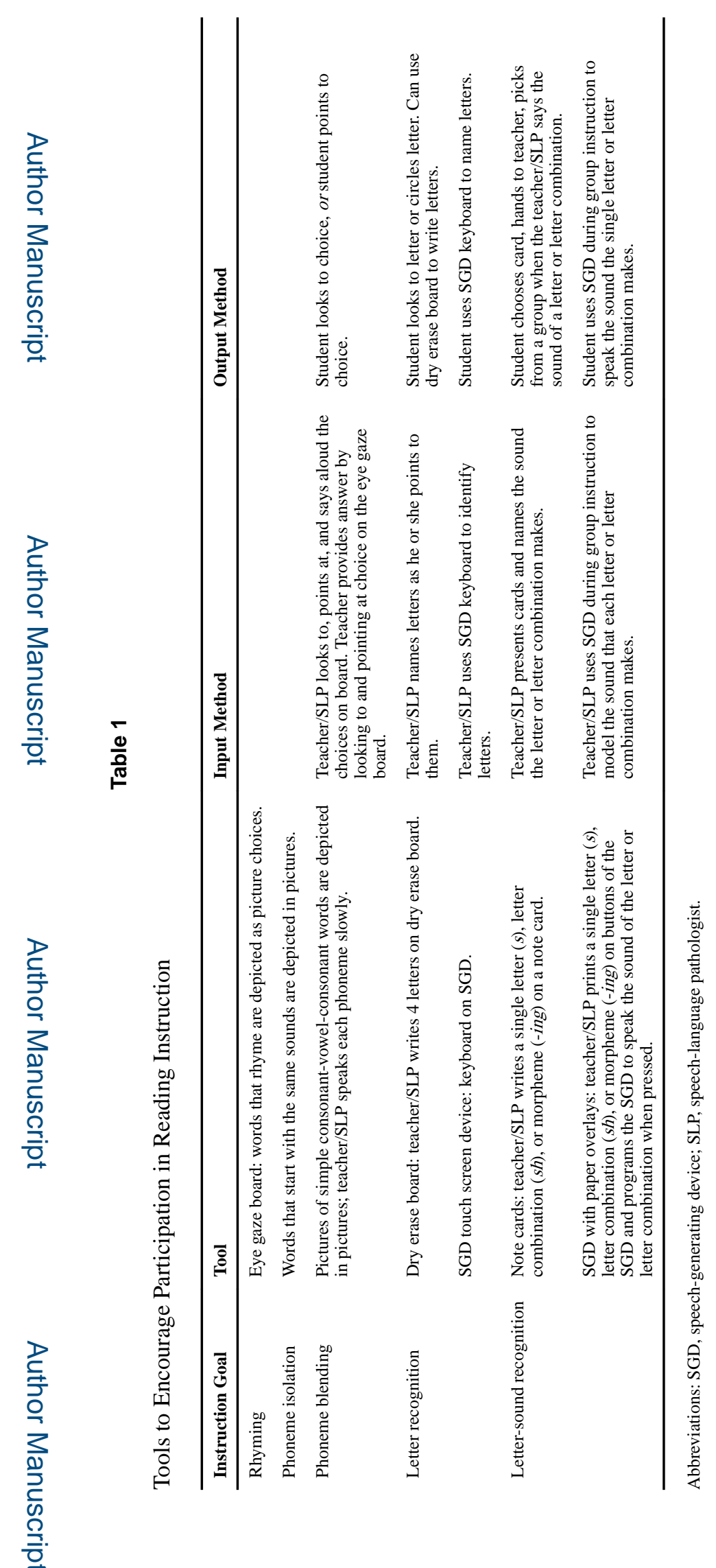

Semin Speech Lang. Author manuscript; available in PMC 2019 February 24. 